\title{
PATTERNS OF PRESCRIPTION IN A PSYCHIATRY OUT PATIENT DEPARTMENT IN A TEACHING HOSPITAL IN BANGLADESH
}

\author{
OMMA HAFSA ANY ${ }^{1}$, FEROZA PARVEEN ${ }^{2}$, FERDOUS ARA ${ }^{3}$, MOHAMMAD JU IQBAL ${ }^{4}$, REKHA RANI SAHA ${ }^{4}$ \\ ${ }^{1}$ Assistant Professor, Department of Pharmacology \& Therapeutics, Z.H. Sikder Women's Medical College, Dhaka \\ ${ }^{2}$ Professor \& Head, Department of Pharmacology \& Therapeutics, Green Life Medical College, Green Road, Dhaka. \\ ${ }^{3}$ Associate Professor \& Head, Department of Pharmacology \& Therapeutics, Sir Sallimullah Medical College, Mitford, Dhaka. \\ ${ }^{4}$ Assistant Professor, Department of pharmacology \& therapeutics, Sir Sallimullah Medical College, Mitford, Dhaka.
}

\begin{abstract}
A cross-sectional descriptive study was carried out among individuals attending the psychiatry outpatient department from February $1^{\text {st }} 2010$ to April $30^{\text {th }} 2010$ in Sir Salimullah Medical College and Mitford Hospital, Dhaka, Bangladesh to see the patterns of prescription and drug use in psychiatry out-patient department of teaching hospital in Bangladesh.A total of 300 patient were included in this study. The average number of drugs per encounter was 2.44 drugs were prescribed by generic name. The commonest clinical indication were schizophrenia and other psychotic disorder (40\%) and use of psychotropic drug (36\%) frequently but injection use(8.33\%) was very low, additional (anticholinergic) drugs were prescribed $76 \%$ of prescription. Average cost of drugs per prescription was 181 taka. So, the study will help to understand the trends in prescribing psychotropic drugs and will provide guidelines for designing appropriate future intervention strategies in order to promote rational prescribing and improve the quality of health care.
\end{abstract}

Keywords: Psychotropic drugs, Prescribing patterns, Drug utilization.

(Bangladesh J Physiol Pharmacol 2012;28(1\&2):19-22.)

\section{INTRODUCTION}

Psychiatric disorders are common in patients at general practitioners. Psychotropic drugs are one important mode of treatment and prescribed frequently. ${ }^{1}$ Today mental health and mental illness are key public health issues. A large number of people worldwide suffer from mental disorders and many more around them encounter the impact of these illness. According to the WHO at least 40 million people in the world suffer from mental disorder such as schizophrenia and dementia. ${ }^{2}$ Rational drug prescribing is defined as the use of the least number of drugs to obtain the best possible effect in the shortest period and at a reasonable cost. ${ }^{3}$ Studies conducted on drug use in health facilities of Bangladesh describes drug use patterns, prescribing behaviour, cost analysis and effect of interventions. ${ }^{4,5,6}$ The assessment of drug utilization is important for clinical, educational and economic purpose. Prescribing patterns need to be evaluated periodically to increase the therapeutic efficacy, decrease adverse effects and provide feedback to prescribers'. ${ }^{7}$ Drug utilization reviews are useful for obtaining information about drug use patterns and for identifying high cost drugs. $5,8,9,10,11,12$ Medical audit oversees the observance of standards of medical care at

Address for correspondence: Dr. Omma Hafsa Any, Assistant Professor, Department of Pharmacology \& Therapeutics, Z H Sikder Women's Medical College, Dhaka. E-mail: hafsaomma@yahoo.com; Mobile: 01676714083 all levels of the health care delivery system". ${ }^{5}$ Mental illness is most neglected disease in Bangladesh, although a large number of people are suffering from different types of mental illness.

\section{MATERIALS AND METHODS}

A cross- sectional descriptive study was carried out at the Sir Salimullah Medical College and Hospital (SSMC \& MH), a tertiary care hospital, Dhaka. The study was carried out over a 90 days period of February $1^{\text {st }} 2010$ to April $30^{\text {th }}$ 2010.The patients and their prescriptions were used as source of data. A total 300 patients were included in this study. The average number of drugs per prescription, most common diagnosis, most commonly prescribed psychotropic drugs, percentage of drugs prescribed by trade name were also noted and percentage of encounters with an injection prescribed. The number of combination preparations and the average cost of drugs per prescription were also calculated. The data was expressed as percentage, mean and total numbers.

\section{RESULTS}

A total of 732 individual drugs were prescribed for 300 drug encounters, giving an average of 2.44 . 
Table I

Shows the average number of drugs per prescription

\begin{tabular}{c|cc}
\hline Total number of prescription & Total numbers of drugs & Average number of drugs \\
\hline 300 & 732 & 2.44 \\
\hline
\end{tabular}

The range of drugs per encounter varied from 1-5,As shown in Table II, two (02) drug were prescribed in 96 prescriptions (32.00\%) was found to be highest among 300 prescriptions.

Table II

Shows the incidence of polypharmacy

\begin{tabular}{c|cc}
\hline $\begin{array}{c}\text { Number of drugs per } \\
\text { prescription }\end{array}$ & Number of prescription & Percentage \\
\hline 0 & 01 & $00.33 \%$ \\
1 & 71 & $23.66 \%$ \\
2 & 96 & $32.00 \%$ \\
3 & 61 & $20.33 \%$ \\
4 & 69 & $23.00 \%$ \\
5 & 02 & $00.66 \%$ \\
Total & 300 & $100.00 \%$ \\
\hline
\end{tabular}

The most commonly prescribed psychotropic drugs was atypical antipsychotic drugs $258(36.00 \%)$, the most commonly prescribing psychotropic drugs are shown in Pie diagram.

Pie diagram shows the type of psychotropic drugs prescribed

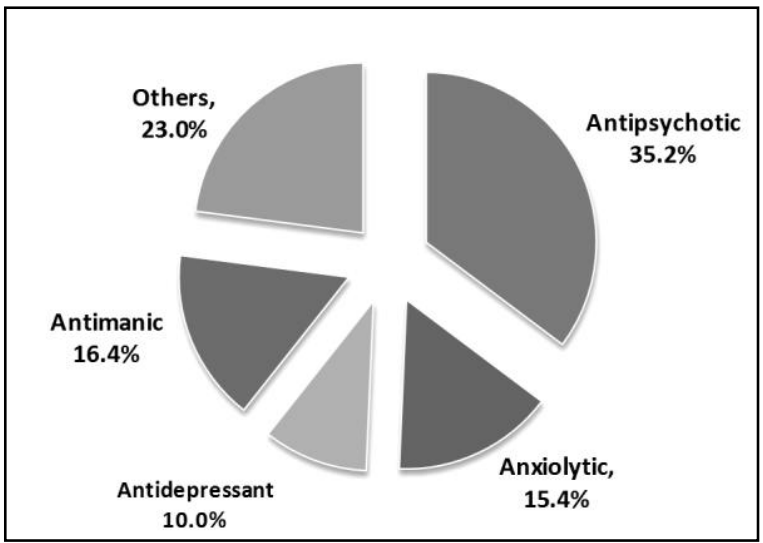

Drugs were not prescribed by generic names and out of 300 prescriptions additional drugs (anticholinergic drugs) 228 (76\%) were prescribed.

Pie diagram Shows the drugs prescribed to counter the adverse effects of psychotropic drugs

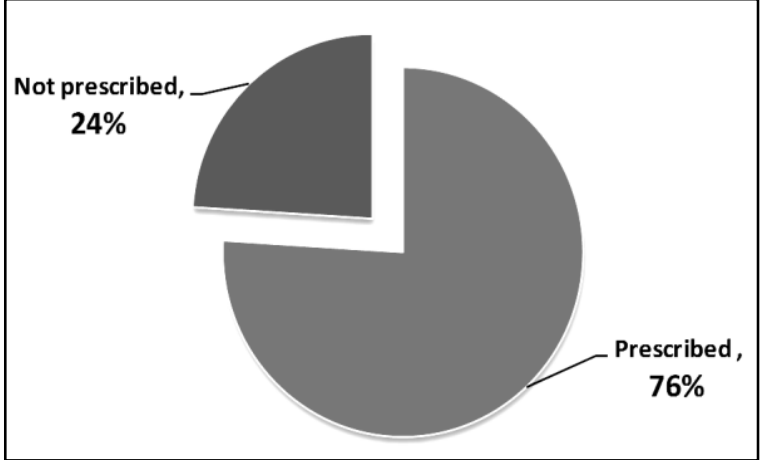


Schizophrenia and other psychotic disorder (40\%) were the most common complaints/disorder among the patient attending psychiatry OPD. The other common complaints/ disorders were bipolar mood disorder (39\%), depressive disorder (9.66\%), anxiety disorder $(2.66 \%)$, somatoform disorder $(1.66 \%)$, mental retardation $(1.66 \%), \mathrm{OCD}(2 \%)$ and others (3.33\%).

\section{Pie diagram shows the psychiatric disorder for which psychotropic drugs were prescribed}

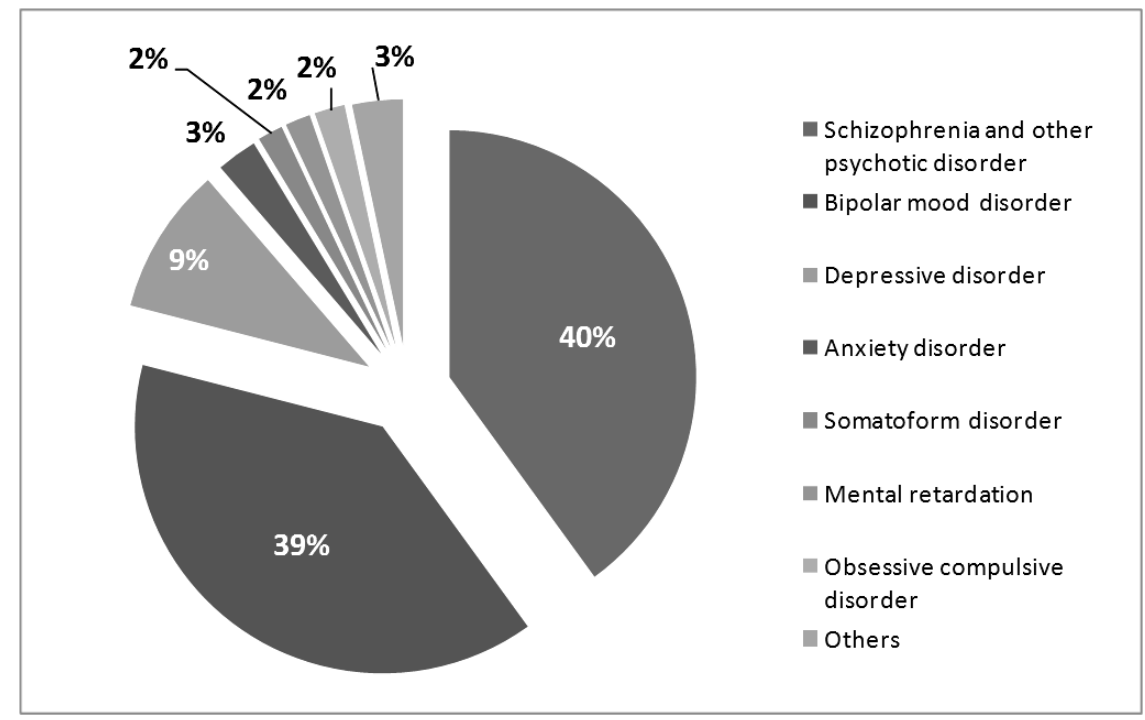

\section{DISCUSSION}

A total of 300 prescriptions containing Psychotropic drugs were collected from patients attending the Psychiatry out-patient Department of teaching hospital in Dhaka city. Schizophrenia and other psychotic disorder (40\%) were the most common complaints/disorder among the patient attending psychiatry OPD. In a study, in Germany, the most common complaints are Schizophrenic psychosis $(50 \%) .{ }^{13}$ This rate is very similar to present rate. In Nepal, Somatoform disorder (26\%) were the most common complaints. ${ }^{14}$ The other common complaints/ disorders were bipolar mood disorder (39\%), depressive disorder (9.66\%), anxiety disorder (2.66\%), somatoform disorder $(1.66 \%)$, mental retardation $(1.66 \%)$, OCD (2\%) and others (3.33\%). Only $8.33 \%$ of the drugs were prescribed by parenteral formulation, minimum use of injections is preferred and this reduces the risk of infection through parenteral route and cost incurred in therapy. ${ }^{1}$ In this study, $300(100 \%)$ of the drugs were prescribed by trade name. The percentage of drugs prescribed by generic name was $0 \%$ in the study which is very much less than that reported in studies conducted in Cambodia ${ }^{15}(99.8 \%)$, India ${ }^{16}$ (73.4\%) and $\mathrm{Nepal}(21.3 \%) .{ }^{17}$ The most common reasons for not prescribing generic name in Bangladesh may be tradition, low production of generic drugs in Bangladesh and currently, most of the pharmaceutical companies' divertive drug promotion technique. ${ }^{4}$ The average number of drugs per prescription was 2.44. In Japan, they received 2.5 drugs per prescription. ${ }^{18}$ In Brazil, 2.30 drugs per prescription. ${ }^{19}$ This rate is very similar to present rate. In the treatment of patients with schizophrenic disorders, this discrepancy becomes particularly clear where combination therapy is the rule in clinical practice. In this regard, an increase has been observed in the use of combination treatment. ${ }^{21}$ Indeed, among therapy resistant affective disorder, a growth in polypharmacy has also been noted. The frequency of polypharmacy increases with the length and severity of the illness. ${ }^{22}$ Women patients were prescribed more Psychotropic drugs than men. Majority of the patients (32\%) received 2 drugs per prescription. The drugs were generally prescribed for time duration of 15 days. The average cost of drugs per prescription was 181 taka for 15 days duration. Additional drugs were prescribed $288(76 \%)$ prescription to counter the extrapyramidal effects. Psychotropic medications are widely prescribed $^{23,24}$ and the utilization of psychotropic drugs is a topic of increasing interest.

\section{CONCLUSION}

Overall prescribing patterns of Psychotropic drugs among the Sir Salimullah Medical College \& Mitford hospital is good and satisfactory. Appropriate educational intervention should be designed for rational prescribing to improve the quality of health care. 


\section{REFERENCES}

1. Linden $M$, Lecrubier $Y$, Bellantuono $C$, Benkert $O$, Kisely $S$, Simon G. Psychotropic drug prescription in primary care. J Euro Psych 1996; 11: S 4: 179s.

2. Fahmida A, Wahab MA, Rahman MM. Pattern of psychiatric morbidity among the patients admitted in a private psychiatric clinic. Bang J Med Sci 2009; 8: 1-2.

3. Gross F. Drug utilization therapy and practice. The present situation in Fedral Republic of Germany. Eur J Clin Pharmacol 1981; 19: 387-94.

4. Rahman MS, Begum M, Khan IA, Chowdhury S, Islam AMZ, Sultana R, Hoque MZ, Akhter N. A Baseline Survey on the Use of Drugs at Private Practitioner Level in Bangladesh. Bang J Physiol Pharmacol 1998: 14(2): 47-50.

5. Islam MS, Rahman MS, Misbahuddin M. Impact of 'Prescription Audit \& Feedback' on Pattern of Prophylactic Antimicrobials in Caesarean Section: a Cost Reduction Perspective. Bang J Physiol Pharmacol 2007: 23: 1-9.

6. Chowdhury AK, Rahman MS, Faroque AB, Hasan GA, Raihan SZ. Excessive use of avoidable therapeutic injections in the upazilla health complexes of Bangladesh. Mymensingh Med $\mathrm{J}$. 2008: 17(2 Suppl): S59-64.

7. World Health Organization (WHO). Action programme for essential drugs. How to investigate drug use in health facilities. WHO, 1993.

8. Pradhan SC, Shedwade DG, Shashindran $\mathrm{CH}$, Bapan JS. Drug utilization studies. National Med J India 1988; 1: 185-189.

9. Krishnaswamy K, Dinesh Kumar B, Radhaiah GA. Drug use survey-precepts and practice. Eur J Clin Pharmacol 1985; 29: 363-370.

10. Uppal $R$, Nayak $P$, Sharma PL. Prescribing trends in internal medicine. Int J Clin Pharm Ther Toxicol 1984; 22: 363-370.

11. Mashner JP, Thurmann P, Harder S, Rietbroc N. Drug utilization review on a surgical intensive care unit. Int J clin Pharmacol Ther 1994; 32: 447-451.

12. Gupta N, Sharma D, Garg SK, Bhargava VK. Auditing of prescription to study antimicrobials in a tertiary hospital. Indian J Pharmacol 1997; 29: 411-15.
13. Bernd R. Brùggemann, Hermann Elgeti, Marc Ziegenbein. Patterns of drug prescription in a psychiatry outpatient care unit. German J Psychiatry 2008; 11: 1-6.

14. Shankar PR, S Roy. Patterns of Prescription and Drug use in a Psychiatry out-patient department in a teaching hospital in Western Nepal. Int J Pharmacol 2002; 1: 2.

15. Chareonkul C, Khun VL, Boonshuyar C. Rational drug use in Cambodia: study of three pilot health centers in Kampong Thom Province. Southeast Asian J Trop Med Public Health 2002; 33: 418-424.

16. Karande $S$, Sankhe $P$, Kulkarni $M$. Patterns of prescription and drug dispensing. Indian J Pediatr 2005;72:112-121.

17. Ghimire S, Nepal S, Bhandari S, Nepal P, Palaian S.A prospective surveillance of drug prescribing and dispensing in a teaching hospital in Western Nepal. J Pak Med Assoc 2009; 59: 726-731.

18. Keohavong B, Syhakhng L, Sengaloundeth S, Nishimura A, Ito K. Pharmacoepidemology Drug Safety 2006; 15: 344-247.

19. de Oliveira J, Naves S, Dee Silver L. Evaluation of Pharmaceutical assistance in public primary care in Brasília, Brazil. Rev Saúde Pública 2005; 39: 223-30.

20. Messer T, Tiltscher C, Schmauss M. Polypharmacy in the treatment of schizophrenia [German]. Fortschr Neurol Psychat 2006; 74: 377-391.

21. Clark RE, Bartels SJ, Mellmann TA, Peacock WJ. Recent trend in antipsychotic combination therapy of schizophrenia and schizoaffective disorder: implications for state mental health policy. Schizophr Bull 2002; 28: 75-84.

22. Frye MA, Ketter TA, Leverich GS, Huggins T, Lant C, Denicoff $K D$, Post RM. The increasing use of polypharmacotherapy for refractory mood disorders: 22years of study. J clin Psychiatry 2000; 61: 9-15.

23. Linden M, Scheel T, Xaver EF. Dosage finding and outcome in the treatment of schizophrenia in patients with amisulpride. Results of a drug utilization observation study. Hum psychopharmacol 2004;19:119.

24. Pincus HA, Taniclian TL, Marcus SC, Olfson M, Zarin DA, Thompso J et care, psychiatry, and other medical specialities. JAMA 1998; 279: 526-31. 